Supplementary Materials for:

\title{
EPR Study of Dialkyl Nitroxides as Probes to Investigate the Exchange of Solutes between the Ligand Shell of Monolayers of Protected Gold Nanoparticles and Aqueous Solutions
} M. Lucarini, P. Franchi, G. F. Pedulli, P. Pengo, P. Scrimin, and L. Pasquato

General procedure for the preparation of $p$-alkylbenzyl hydroxyalkyl amines. 2-methylalanine $(100 \mathrm{mmol})$ was dissolved in $\mathrm{NaOH} 2 \mathrm{M}(60 \mathrm{ml})$ and cooled in an ice bath $\left(0^{\circ} \mathrm{C}\right)$. The appropriate $p$ alkyl benzoyl chloride $(100 \mathrm{mmol})$ and $\mathrm{NaOH} 2 \mathrm{M}(60 \mathrm{ml})$ were added simultaneously in ten portions every three minutes. The solution was stirred for an additional $45 \mathrm{~min}$. at room temperature, then was cooled and treated with concentrated $\mathrm{HCl}$. After $2 \mathrm{~h}$ the suspension was filtered and the solid was washed with acetone, before being dried $\left(\mathrm{MgSO}_{4}\right)$. Acetone was removed by evaporation under reduced pressure to afford the amide in $90-99 \%$ yield. The amide $(40 \mathrm{mmol})$ was then dissolved in anhydrous THF (200 ml) and added dropwise to a suspension of $\mathrm{LiAlH}_{4}(80 \mathrm{mmol})$ in anhydrous THF $(100 \mathrm{ml})$ over a period of $30 \mathrm{~min}$. The reaction mixture was stirred and heated under gentle reflux under $\mathrm{N}_{2}$ for $2 \mathrm{~h}$. The solution was cooled and stirred with ethyl acetate $(100 \mathrm{ml})$ and $\mathrm{H}_{2} \mathrm{O}(100 \mathrm{ml})$, before being filtered. The organic phase was extracted with $\mathrm{Et}_{2} \mathrm{O}(3 \times 80 \mathrm{ml})$, before being dried $\left(\mathrm{MgSO}_{4}\right)$. The solvent was removed by evaporation under reduced pressure to give the amine in 70 $80 \%$ yield. All the products were characterized by NMR and GC-MS. Representative data for the amine precursors of $3:{ }^{1} \mathrm{H}$ NMR $\left(\left(\mathrm{CD}_{3}\right)_{2} \mathrm{SO}\right) \delta 7.21(\mathrm{~d}, 2 \mathrm{H}), 7.09(\mathrm{~d}, 2 \mathrm{H}), 4.54($ broad s, $\mathrm{NH}), 3.57(\mathrm{~s}$, 2H), $3.22(\mathrm{~s}, 2 \mathrm{H}), 2.53(\mathrm{t}, 2 \mathrm{H}), 1.49(\mathrm{~m}, 2 \mathrm{H}), 1.28(\mathrm{~m}, 2 \mathrm{H}), 0.98(\mathrm{~s}, 6 \mathrm{H}), 0.88(\mathrm{t}, 2 \mathrm{H}) ; \mathrm{GC}-\mathrm{MS}(\mathrm{m} / \mathrm{z})$ $204\left(\mathrm{M}^{+}-31,33\right), 147\left(\mathrm{M}^{+}-88,100\right)$. 
Stability of MPC-C8-TEG in the presence of Oxone. The stability, in oxidative conditions, of nanoparticles passivated by thiol $\mathbf{1}$ were tested spectrophotometrically using gold clusters with core size of $3.4 \pm 0.7 \mathrm{~nm}$. To a water solution of nanoparticles $(2 \mathrm{ml}$, concentration $0.24 \mathrm{mg} / \mathrm{ml}$ corresponding to a formal concentration of ligand $\left.18.3 \times 10^{-5} \mathrm{~mol} / \mathrm{l}\right), 40 \mu \mathrm{l}$ of Oxone solution (concentration $0.028 \mathrm{M}$ in $\mathrm{KHSO}_{5}$ ) were added (final concentration of $\mathrm{KHSO}_{5}$ in the quartz cell $\left.5.6 \times 10^{-4} \mathrm{~mol} / \mathrm{l}\right)$. After Oxone addition the stability of the nanoparticles were checked spectrophotometrically (see Figure 1S). After five minutes, that is after the required time for recording an EPR spectrum, no significative differences in the UV spectrum were observed. After 15 minutes the UV sepctrum showed a significative broadening and red shifting of the Surface Plasmon Band of the MPCs. This has been taken as an indication of aggregation arising from decomposition of nanoparticles monolayer.

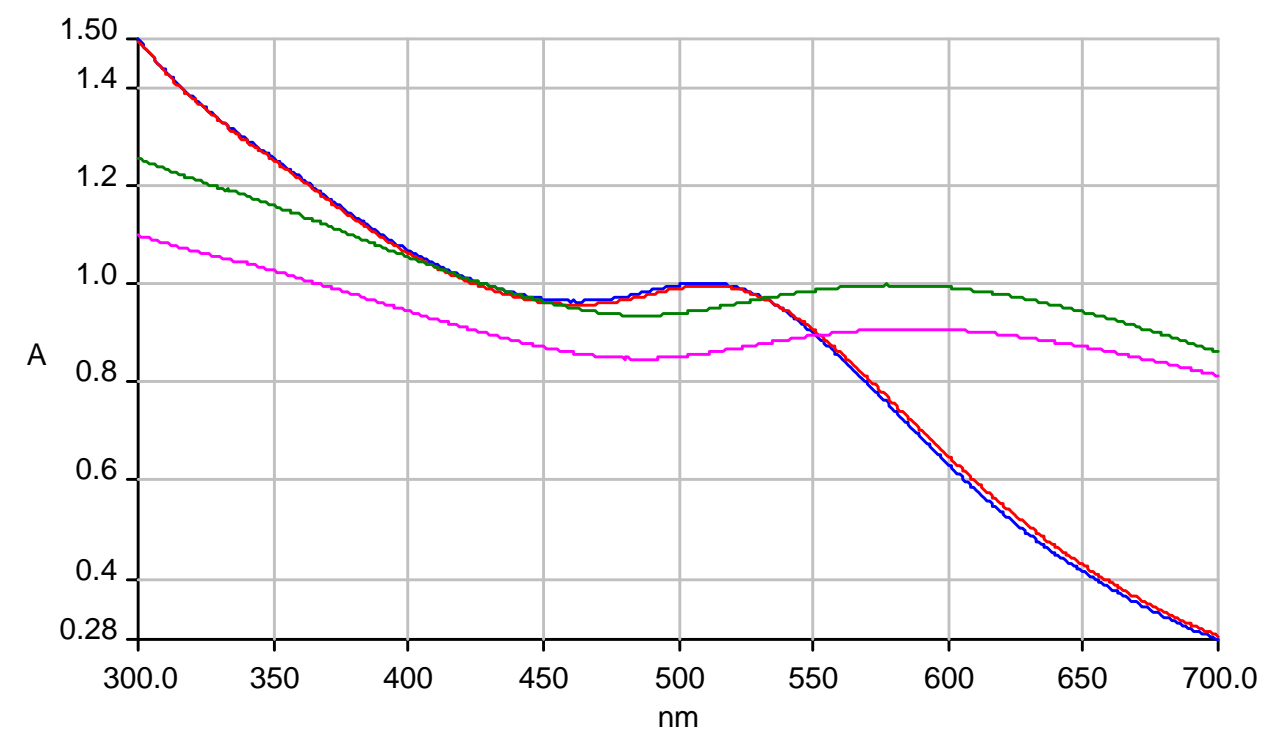

Figure 1S. Red curve: spectrum recorded immediately after Oxone addition. Blue Curve, spectrum recorded after 5 minutes. Green curve: spectrum recorded after 15 minutes. Violet curve: spectrum recorded after 20 minutes. 
Table 1S. Detailed radical ratio determined by EPR measurement of equilibrium constant $K_{\text {eq. }}$

\begin{tabular}{cccc}
\hline \multirow{2}{*}{ Probe } & {$[M P C-C 8-P E G] / m M$} & {$\left[R N\left(O \cdot R^{\prime}\right]_{M P C-C 8-P E G}\right.$} & \multirow{2}{*}{$K_{\text {eq }} / M^{-1}$} \\
\cline { 3 - 3 } & & {$\left[R N\left(O \cdot R^{\prime}\right]_{\text {water }}\right.$} & \\
\hline $\mathbf{2}$ & 0.47 & 1.9 & $4178 \pm 678^{\mathrm{a}}$ \\
& 0.67 & 2.8 & \\
& 1.00 & 4.1 & \\
\hline $\mathbf{3}$ & 1.30 & 5.4 & \\
& 0.47 & 5.4 & $11250 \pm 594$ \\
& 0.67 & 7.2 & \\
\hline $\mathbf{4}$ & 0.82 & 9.3 & \\
& 1.00 & 11.0 & \\
& 0.67 & 4.1 & \\
& 0.87 & 5.5 & \\
\hline $\mathbf{5}$ & 1.00 & 6.7 & \\
& 1.30 & 2.3 & \\
& 0.15 & 4.2 & \\
& 0.30 & 8.0 & \\
\hline
\end{tabular}

${ }^{a}$ Errors correspond to standard error of the regression coefficient.

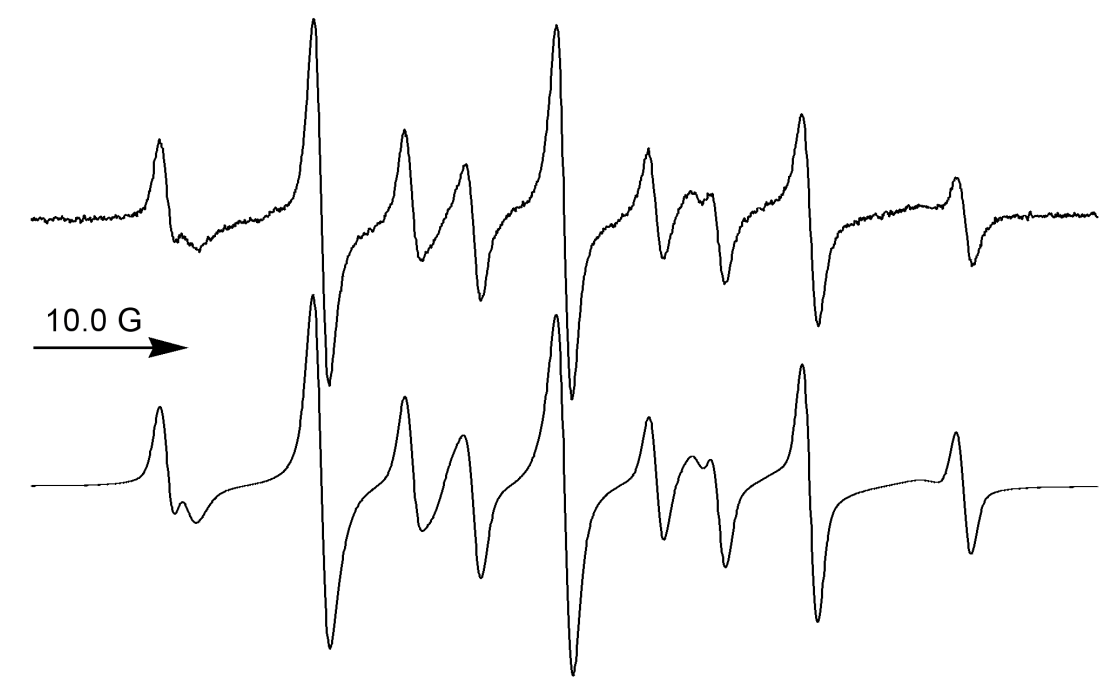

Figure 2S. EPR spectrum of nitroxide 3 recorded in the presence of MPC-C8-TEG $0.47 \mathrm{mM}$ at $298 \mathrm{~K}$ (up) and the corresponding theoretical simulation (bottom). 


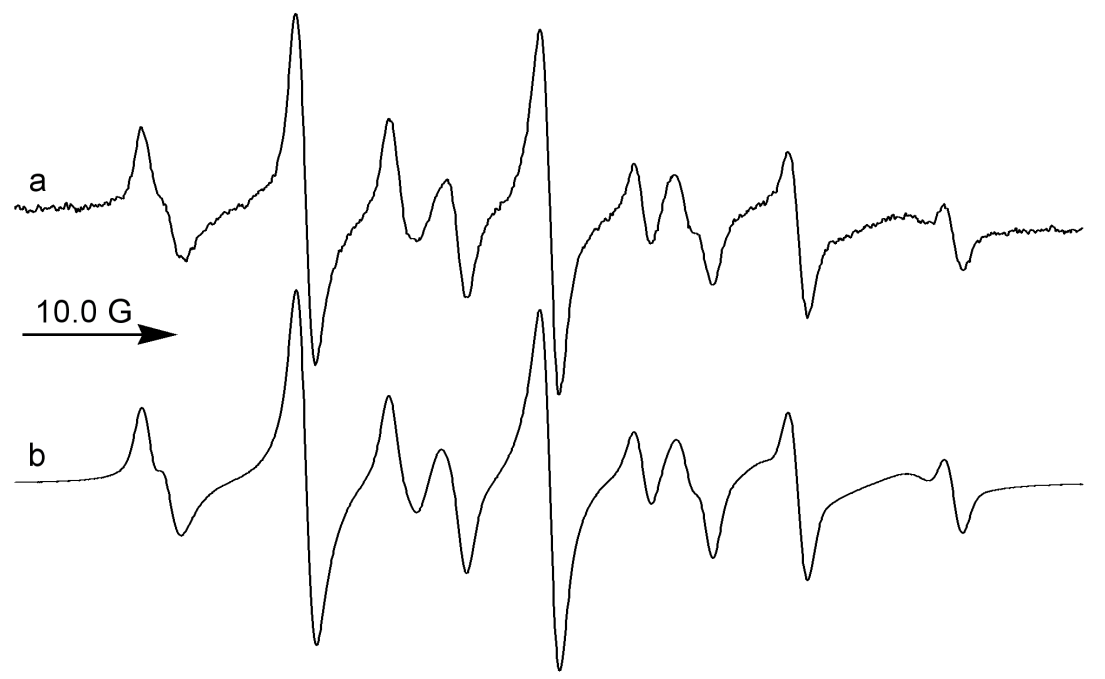

Figure 3S. EPR spectrum of nitroxide 4 recorded in the presence of MPC-C8-TEG 0.97 mM at $298 \mathrm{~K}$ (up) and the corresponding theoretical simulation (bottom).

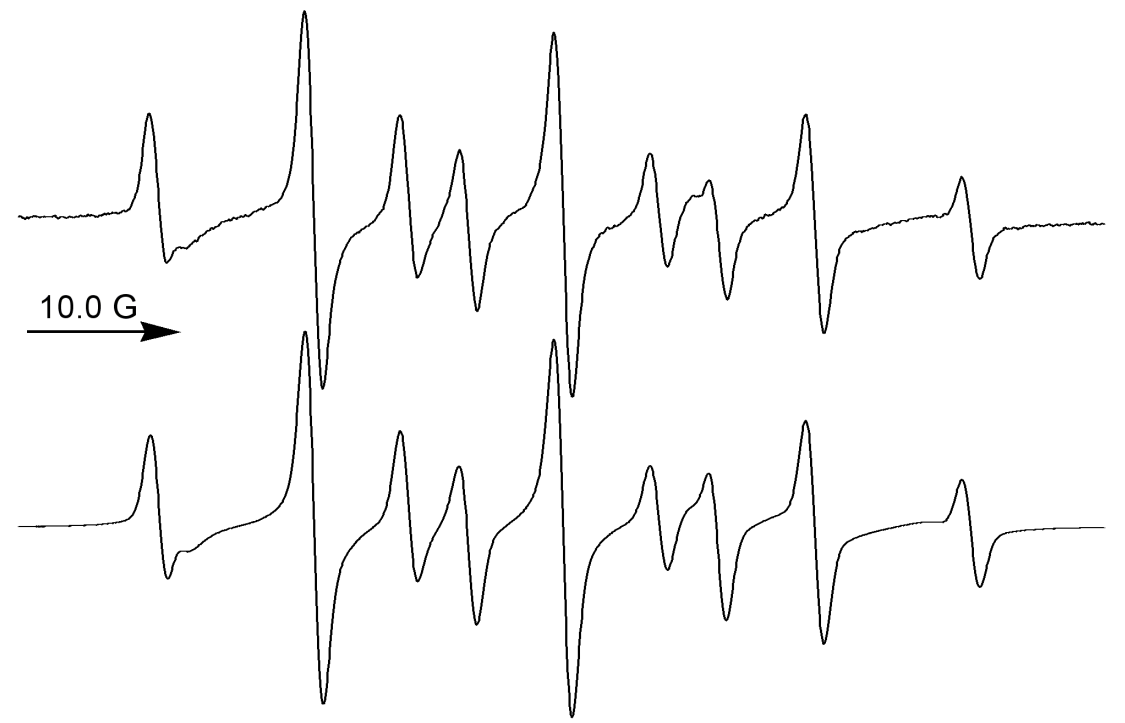

Figure 4S. EPR spectrum of nitroxide 5 recorded in the presence of MPC-C8-TEG 0.97 mM at $298 \mathrm{~K}$ (up) and the corresponding theoretical simulation (bottom). 

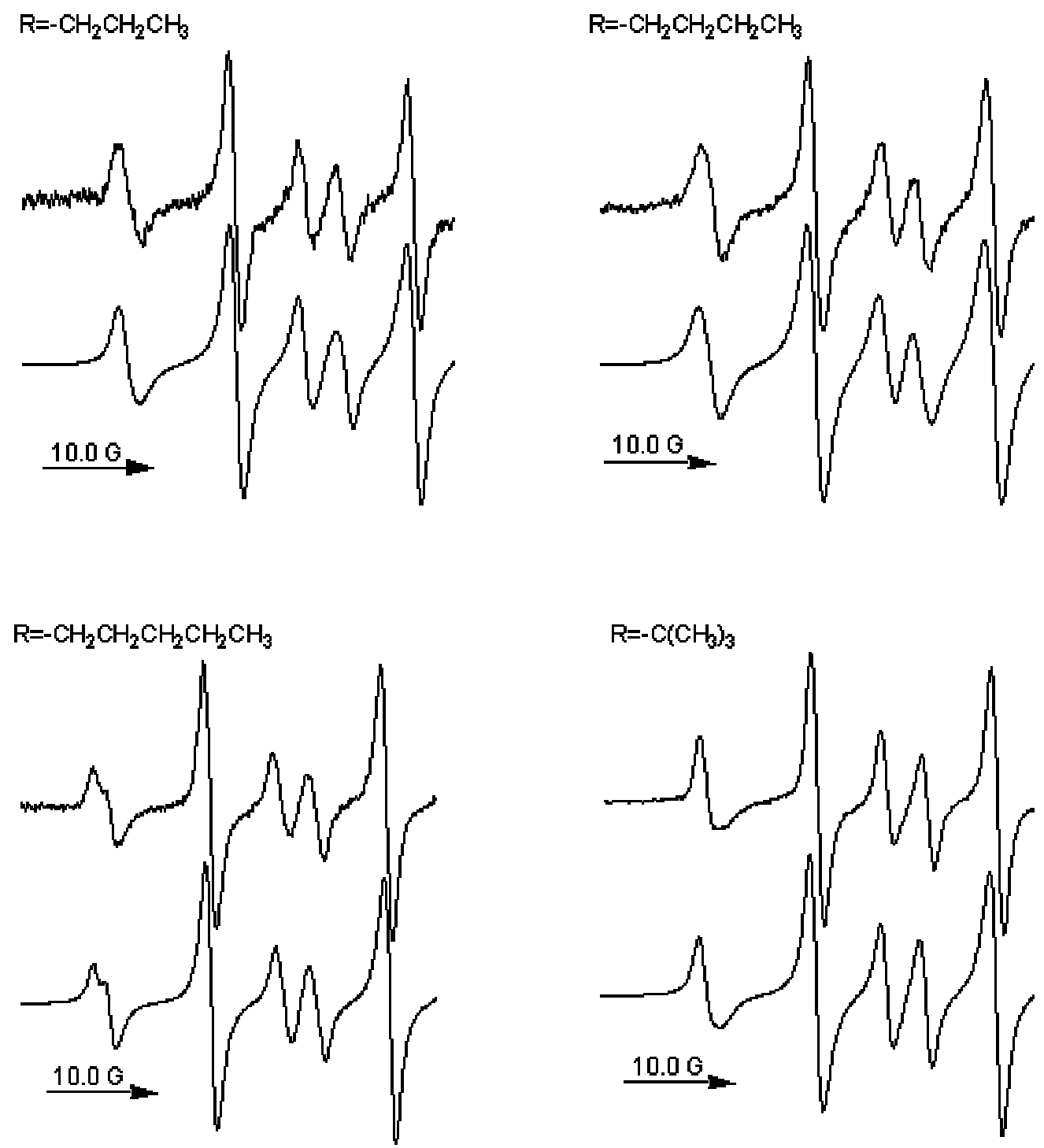

Figure 5S. High field part of the experimental (up) and simulated (bottom) EPR spectra of radicals 3-6 recorded at $310 \mathrm{~K}$ in the presence of MPC-C8-TEG $1 \mathrm{mM} \mathrm{(2-3),0.67} \mathrm{mM} \mathrm{(4)} \mathrm{and} 0.3 \mathrm{mM}(\mathbf{5})$. The corresponding theoretical simulations have been obtained by using the rate constants reported in Table 1. 